\title{
Structural and magnetic properties of gadolinium modified $\mathrm{BiFeO}_{3}$
}

\author{
L.M. Ramírez Guzmán*, A.F. Cruz Pacheco, J.A. Gómez Cuaspud, C.A. Parra Vargas \\ Grupo Fisica de Materiales (GFM), Universidad Pedagógica y Tecnológica de Colombia, Avenida Central del Norte 39-115, \\ 15003, Tunja, Colombia
}

This paper reports the synthesis and characterization of the $\mathrm{Bi}_{0.94} \mathrm{Gd}_{0.06} \mathrm{FeO}_{3}$ sample obtained by solid state reaction method. The structural and morphological analysis was performed by X-ray diffraction (XRD), scanning electron microscopy (SEM) and Rietveld refinement analysis, confirming the obtaining of a rhombohedral crystalline phase and R3c space group $(\mathrm{a}=\mathrm{b}=5.577 \AA$ and $\mathrm{c}=13.847 \AA$ ), with an interconnected structure. Studies by X-ray photoelectron spectroscopy (XPS) revealed trivalent oxidation states of $\mathrm{Bi}, \mathrm{Fe}$ and $\mathrm{Gd}$ ions. The synthesized sample exhibited a non-linear $\mathrm{M}-\mathrm{H}$ loop indicating a weak ferromagnetic behavior with a remnant magnetization of $6.34 \mathrm{emu} \cdot \mathrm{mol}^{-1}$ and a coercive field of $295 \mathrm{Oe}$. The obtained structural and magnetic characteristics make these materials of great interest as multiferroic components.

Keywords: bismuth ferrite; magnetization; multiferroic; solid state reaction; XPS analysis

\section{Introduction}

The multiferroic materials exhibit two or more ferroic properties, such as ferroelectricity, ferromagneticity and ferroelasticity in the same crystalline phase. It is the reason why their fascinating properties have gained a wide interest for technological applications in design of memories [1-3], sensors [4], spintronics [5], transducers [6] and nanogenerators [7]. One of the most frequently studied composition in solid state science and multiferroic systems is the $\mathrm{BiFeO}_{3}$, a perovskite with a rhombohedral crystalline structure and a space group R3c. This antiferromagnetic material (G-type), exhibits a Neel temperature of $640 \mathrm{~K}$ and a ferroelectric temperature around $1100 \mathrm{~K}$, relevant properties for design of structurally ordered magnetic components at room temperature $[8,9]$. Due to its high magnetic and electrical ordering temperatures, the application in the field of practical devices has been limited, because it is difficult to obtain a pure phase of bismuth ferrite, due to the formation of secondary phases, such as $\mathrm{Bi}_{2} \mathrm{Fe}_{4} \mathrm{O}_{9}$, $\mathrm{Bi}_{25} \mathrm{FeO}_{40}$ and $\mathrm{Bi}_{36} \mathrm{Fe}_{24} \mathrm{O}_{57}$, that generate

*E-mail: laura.ramirez01@uptc.edu.co a current loss, which results in a weak ferroelectric behavior. To correct this drawback and improve the magnetic and electrical properties, numerous reports have been published on the modification of bismuth ferrite composition by incorporating rare earth elements at bismuth site, achieving relevant results when substitutions included trivalent ions such as Gd [10-12]. Under this frame of reference, more detailed theoretical and experimental studies on the effect of modification of lanthanide cation in the structure of bismuth ferrite have established that modification values of around $6 \%$ can offer more details about its effect on the most relevant ferroelectric properties for possible technical applications [13-15]. In such works, it has been observed that ferroic properties of $\mathrm{Bi}_{1-\mathrm{x}} \mathrm{Gd}_{\mathrm{x}} \mathrm{FeO}_{3}$ modified by $5 \%$ to $8 \% \mathrm{Gd}$ at site $\mathrm{A}$, provide an improvement in the phase purity and an effective magnetic moment of $8.0 \mu \mathrm{B}$. These results have led to a tunable distortion of the network for controlling the properties of the compound by formation of a solid solution in which the ionic radii of the $\mathrm{Bi}^{3+}$ and $\mathrm{Gd}^{3+}$ play an important role $\left(\mathrm{Bi}^{3+}: 1.170 \AA \mathrm{Gd}: 0.938 \AA\right),[13-15]$. For these reasons, the present work is focused on the synthesis of a modified sample of $\mathrm{BiFeO}_{3}$ with 
$6 \%$ of gadolinium, through the implementation of a solid-state reaction and its respective characterization, in order to observe the effect on the structural and magnetic properties useful for potential technological applications.

\section{Experimental}

The sample of $\mathrm{Bi}_{0.94} \mathrm{Gd}_{0.06} \mathrm{FeO}_{3}$, was prepared from corresponding oxides of $\mathrm{Bi}_{2} \mathrm{O}_{3}, \mathrm{Gd}_{2} \mathrm{O}_{3}$ and $\mathrm{Fe}_{2} \mathrm{O}_{3}$ (99.99\% Sigma-Aldrich). The oxides were weighted and dried in an oven at $200{ }^{\circ} \mathrm{C}$ for 12 hours; at the end of the process, they were ground in an agate mortar for 4 hours and calcined at $700{ }^{\circ} \mathrm{C}$ for 12 hours. The calcined sample was ground for 3 hours and compressed in a pellet form of $10 \mathrm{~mm}$ diameter using a uniaxial pressure of 5.0 MPa. The samples were sintered at $800{ }^{\circ} \mathrm{C}$ for 20 hours in a programmable tubular oven followed by rapid cooling at room temperature.

The structural characterization of the sintered material, was performed by X-ray diffraction (XRD) using a diffractometer PANalytical X'pert PRO-MPD, equipped with a detector Ultrafast $\mathrm{X}$ 'Celerator in Bragg-Brentano configuration, and $\mathrm{CuK} \alpha$ radiation $(\lambda=1.54186 \AA)$ between $20^{\circ}$ and $90^{\circ}$, with steps of $0.02^{\circ}$. The measurements were carried out at a voltage of $40 \mathrm{kV}$ and a current of $20 \mathrm{~mA}$. The structural refinement process was performed using the Rietveld method and the GSAS software. The morphological study of the samples was performed by scanning electron microscopy with a JEOL JSM 6490-LV microscope. The valence states of ions were explored by X-ray photoelectron spectroscopy (XPS). The data were obtained at room temperature using a Thermo Scientific Escalab 250 XI spectrometer, with monochromatic $\mathrm{AlK} \alpha(\mathrm{h} v=1486.6 \mathrm{eV})$ radiation. The analyzer was operated with a pass energy of $25 \mathrm{eV}$ and a step size of $0.05 \mathrm{eV}$. The $\mathrm{C} 1 \mathrm{~s}$ signal $(284.6 \mathrm{eV})$ was used as an internal energy reference in all experiments. The magnetization analysis was performed with a vibrating sample magnetometer (VSM), in a zero-field-cooled-field-cooled (ZFCFC) mode as a function of temperature between $50 \mathrm{~K}$ and $350 \mathrm{~K}$ at several magnetic applied fields (500 Oe, 1000 Oe and 5000 Oe). The magnetic hysteresis measurements were done at $50 \mathrm{~K}$ between $-20 \mathrm{kOe}$ and $20 \mathrm{kOe}$ and the results were analyzed and processed to obtain the corresponding magnetic hysteresis curves.

\section{Results and discussion}

Fig. 1 and Fig. 2 show the XRD pattern and Rietveld refinement of $\mathrm{Bi}_{0.94} \mathrm{Gd}_{0.06} \mathrm{FeO}_{3}$ oxide, which exhibits a rhombohedral perovskite type structure $\mathrm{R} 3 \mathrm{c}$ with cell parameters $\mathrm{a}=\mathrm{b}=$ $5.5770 \AA$ and $c=13.8470 \AA$, in agreement with

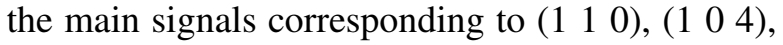
$\left(\begin{array}{lll}2 & 0 & 2\end{array}\right),\left(\begin{array}{lll}1 & 1 & 6\end{array}\right)$ and $\left(\begin{array}{lll}0 & 0 & 6\end{array}\right)$ facets.

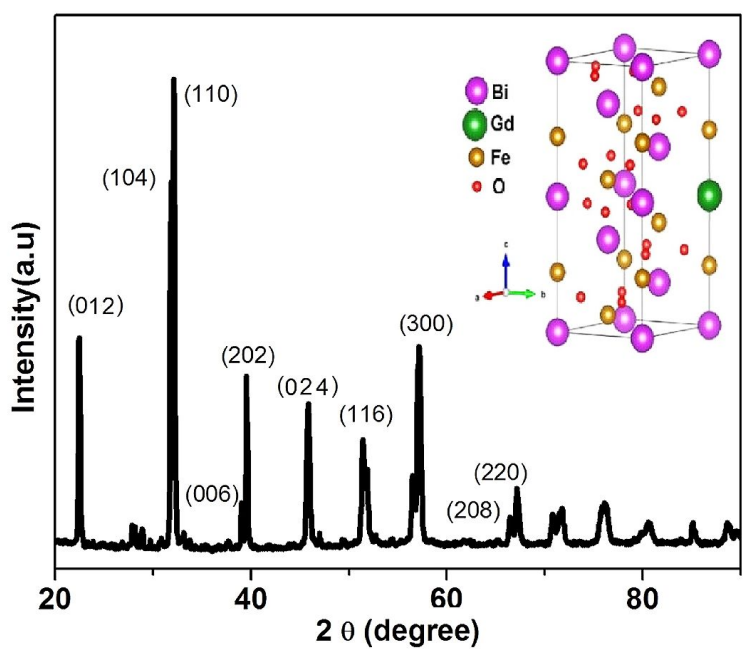

Fig. 1. XRD pattern and structural model for $\mathrm{Bi}_{0.94} \mathrm{Gd}_{0.06} \mathrm{FeO}_{3}$.

The results, derived from Rietveld refinement, listed in Table 1, indicate that $\mathrm{Bi}_{0.94} \mathrm{Gd}_{0.06} \mathrm{FeO}_{3}$ is the main phase of the compound in the amount of around $94.5 \%$, while the concentration of the secondary phase identified as $\mathrm{Bi}_{2} \mathrm{Fe}_{4} \mathrm{O}_{9}$ (marked by ४) is less of $5 \%$. Crystal structure of the sample was identified as an orthorhombic structure (Pbam). According to Uniyal et al. [16], and previous works the kinetics is related to the formation of bismuth ferrite, in which different rare earths have been incorporated into the basic structure of bismuth ferrite. It has been confirmed that reaction conditions, structural properties of reactants, surface area of the solids, their reactivity and thermodynamic free energy changes associated with 
Table 1. Structural parameters for $\mathrm{Bi}_{0.94} \mathrm{Gd}_{0.06} \mathrm{FeO}_{3}$ sample obtained by Rietveld Refinement.

\begin{tabular}{|c|c|c|c|c|c|c|}
\hline \multicolumn{4}{|c|}{ Crystal system } & Space group & & Cell volume $\left[\AA^{3}\right]$ \\
\hline \multicolumn{4}{|c|}{ Rhombohedral } & R3c (167) & & 373.110 \\
\hline \multicolumn{4}{|c|}{ Lattice parameters } & \multicolumn{3}{|c|}{ Statistical parameters } \\
\hline $\mathrm{a}[\AA]$ & 5.577 & $\alpha$ & 90.000 & Rwp [\%] & $\operatorname{Rp}[\%]$ & $x^{2}$ \\
\hline $\mathrm{b}[\AA]$ & 5.577 & $\beta$ & 90.000 & 5.44 & 3.95 & 4.44 \\
\hline$c[\AA]$ & 13.847 & $\gamma$ & 120.000 & & & \\
\hline
\end{tabular}

Atomic positions

\begin{tabular}{ccccc} 
& $\mathrm{Bi}$ & $\mathrm{Gd}$ & $\mathrm{Fe}$ & $\mathrm{O}$ \\
$\mathrm{x}$ & 0.000 & 0.000 & 0.000 & 0.901 \\
$\mathrm{y}$ & 0.000 & 0.000 & 0.000 & 0.226 \\
$\mathrm{z}$ & -0.001 & -0.001 & 0.222 & 0.619 \\
$\mathrm{OCC}$ & 0.940 & 0.060 & 1.000 & 1.000 \\
\hline
\end{tabular}

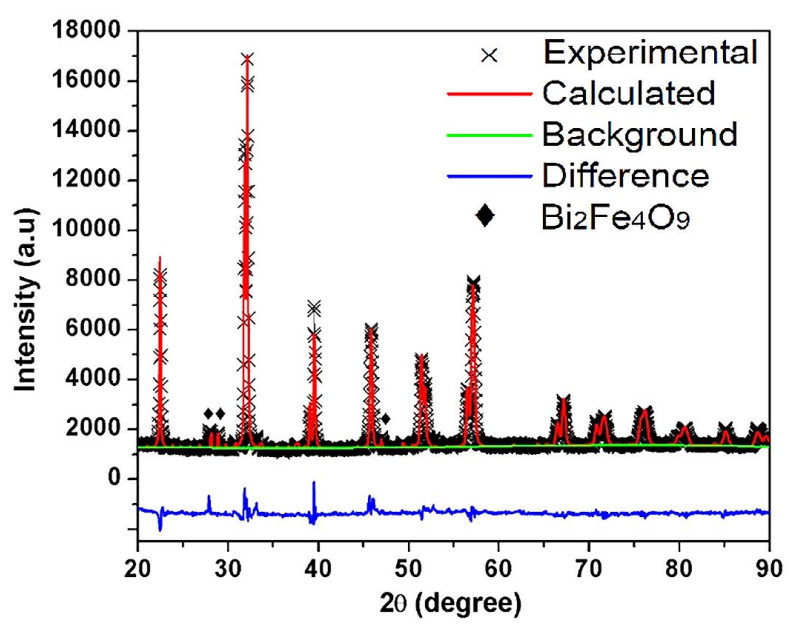

Fig. 2. Rietveld refinement of $\mathrm{Bi}_{0.94} \mathrm{Gd}_{0.06} \mathrm{FeO}_{3}$ with corresponding secondary phase of $\mathrm{Bi}_{2} \mathrm{Fe}_{4} \mathrm{O}_{9}$ $(\diamond)$.

the reaction cannot be easily controlled at temperatures below $850{ }^{\circ} \mathrm{C}[16,17,19]$.

In the same way, works reported by Vijayasundaram et al. [20], using gadolinium modifications in bismuth ferrites, allowed to establish that gadolinium modifications could produce several distortions leading to obtaining rhombohedral structures, but in all cases, the most important crystallographic parameters remained unchanged with some variations, which led to obtaining of materials with orthorhombic structure and defined cell parameters $[18,21]$.
Fig. $3 a$ and Fig. $3 b$ show the scanning electron images that reveal the morphology of the $\mathrm{Bi}_{0.94} \mathrm{Gd}_{0.06} \mathrm{FeO}_{3}$ powder with an irregular distribution of grains and an interconnected structure. The photomicrographs reveal particles that have different shapes and sizes, with an irregular surface and a tendency to agglomerate in accordance with synthesis method.

The result of X-ray photoelectron spectroscopy analysis between $0 \mathrm{eV}$ and $1200 \mathrm{eV}$ is shown in Fig. 4, revealing the binding energy of each element, where peak deconvolution and fitting data show that the experimental peaks could be fitted by the corresponding peaks associated to each cation.

The detailed analysis of oxidation state and binding energy of bismuth was carried out for trivalent state of $\mathrm{Bi}\left(\mathrm{Bi} 4 \mathrm{f}_{7 / 2}\right.$ and $\left.\mathrm{Bi} 4 \mathrm{f}_{5 / 2}\right)$ that is observed at $157 \mathrm{eV}$ and $162.3 \mathrm{eV}$ as shown in Fig. 5a. Additionally, the signals related with $\mathrm{Bi} 4 \mathrm{~d}_{5 / 2}$, Bi $4 \mathrm{~d}_{3 / 2}$ and $\mathrm{Bi} 4 \mathrm{p}_{3 / 2}$ located at $441.3 \mathrm{eV}, 463 \mathrm{eV}$ and $679.7 \mathrm{eV}$, respectively, confirm the effectiveness of the synthesis method and Gd modification level to stabilize the $\mathrm{Bi}$ in the perovskite structure.

The occurrence of signals associated with gadolinium in its trivalent state in the region Gd 2p, whose peaks are mainly located at $1082.8 \mathrm{eV}$ and $1109.5 \mathrm{eV}$ is clearly seen in Fig. 5b. The low intensity of the signal indicates the level of modification of $6 \%$ in the solid, in agreement with previous works of Lotey et al. [22, 23]. 


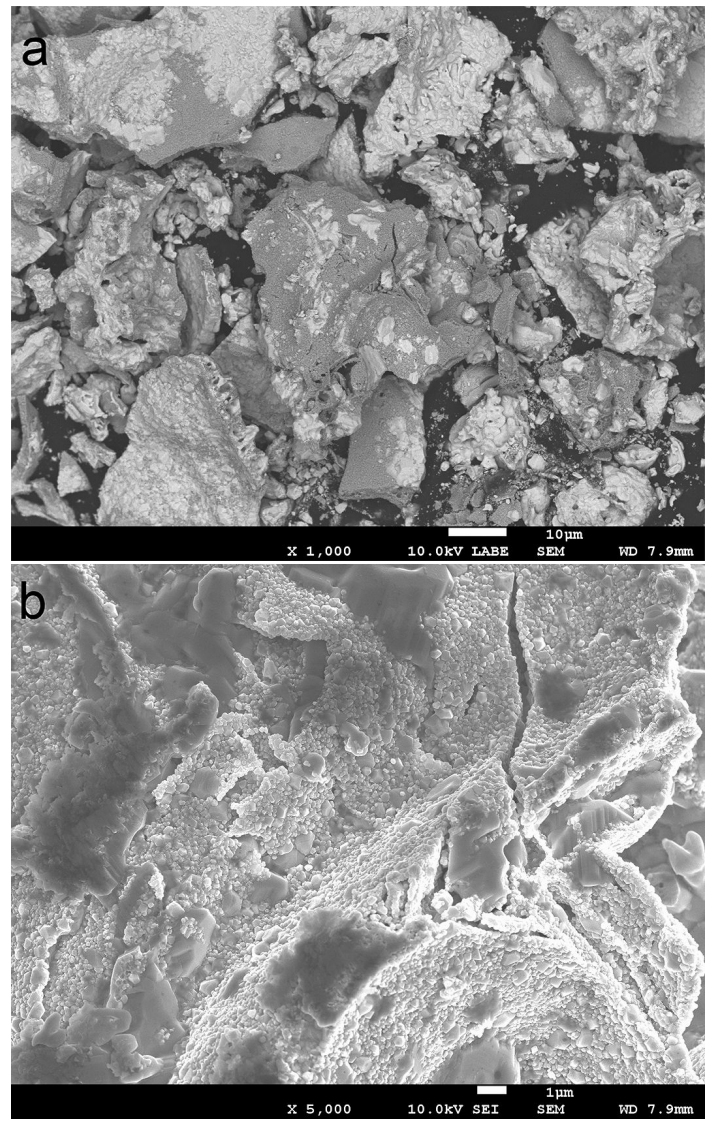

Fig. 3. Scanning electron images for $\mathrm{Bi}_{0.94} \mathrm{Gd}_{0.06} \mathrm{FeO}_{3}$ sample at (a) $\times 1000$ and (b) $\times 5000$ magnifications.

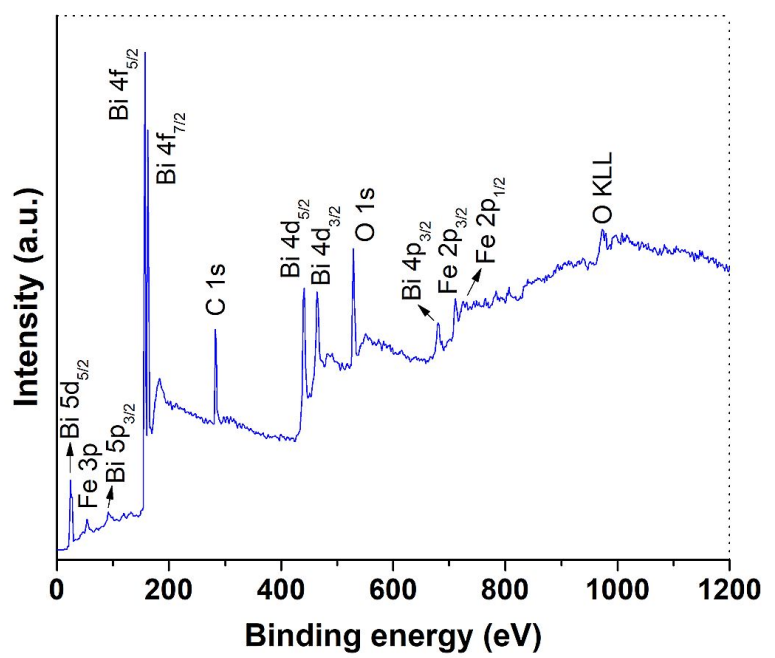

Fig. 4. General scan of X-ray photoelectron spectroscopy analysis of $\mathrm{Bi}_{0.94} \mathrm{Gd}_{0.06} \mathrm{FeO}_{3}$ sample.
Fig. 5c shows the spectral region related to $\mathrm{Fe}$ $2 p$, in which the presence of two peaks of low $\left(\mathrm{Fe} 2 \mathrm{p}_{3 / 2}\right)$ and high energy ( $\left.\mathrm{Fe} 2 \mathrm{p}_{1 / 2}\right)$ is associated with the chemical state of $\mathrm{Fe}^{3+}$ derived from spin-orbital splitting [24]. According to literature, the standard signals $\mathrm{Fe} 2 \mathrm{p}_{3 / 2}$ and $\mathrm{Fe} 2 \mathrm{p}_{1 / 2}$, which are found between $706.7 \mathrm{eV}$ to $719.8 \mathrm{eV}, 709.2 \mathrm{eV}$ to $722.8 \mathrm{eV}$ and $711.2 \mathrm{eV}$ to $724.8 \mathrm{eV}$, respectively correspond to +3 valence. According to Bellakki and Manivannan [25], gadolinium does not promote the +2 oxidation state in the sample which allows one to avoid phase segregation and contamination of $\mathrm{Bi}_{0.94} \mathrm{Gd}_{0.06} \mathrm{FeO}_{3}$ [25-28].

The signal observed at $528.32 \mathrm{eV}$ is assigned to $\mathrm{O} 1 \mathrm{~s}$ which is attributed to the oxidation state $\mathrm{O}^{2-}$ as shown in Fig. 5d. The adjustment and analysis of the second signal at $530.5 \mathrm{eV}$ is attributed to the $\mathrm{O}^{2-}$ ions surrounded by bismuth atoms and the supply of the -OH groups linked to material surface in form of absorbed water as it was postulated by Gupta et al. [6]. Particularly, the XPS results confirm that there is no evidence of metallic Fe or a ferrimagnetic arrangement due to $\mathrm{Fe}^{2+}$, which proves the effect of Gd cation as a structure stabilizer in such modification level. Otherwise, a possible increase in the canting angle of $\mathrm{Fe}$ ions which could be associated with oxygen vacancies, could be the reason why the magnetization analysis is necessary to clarify this aspect.

The magnetization as function of magnetic field was investigated at $50 \mathrm{~K}$ between $-20000 \mathrm{Oe}$ and 20000 Oe, and is shown in Fig. 6. The magnetic response of the sample exhibits a weak ferromagnetic behavior, which can be evidenced by the remnant magnetization of approximately $6.34 \mathrm{emu} \cdot \mathrm{mol}^{-1}$ and a coercive field around 295 Oe. Such result is in an agreement with the magnetic response reported in literature, in which the hysteresis cycle is not linear and is related to the effect of Fe sublattice that is primarily responsible for magnetization at room temperature, while the ordering assigned to the rare earth substitutions contributes slightly to magnetization in accordance with previous works [26, 27].

According to Suresh et al. [28], the nonlinear $\mathrm{M}-\mathrm{H}$ curves show an increase in the remnant magnetization when the value of the doping increases, 


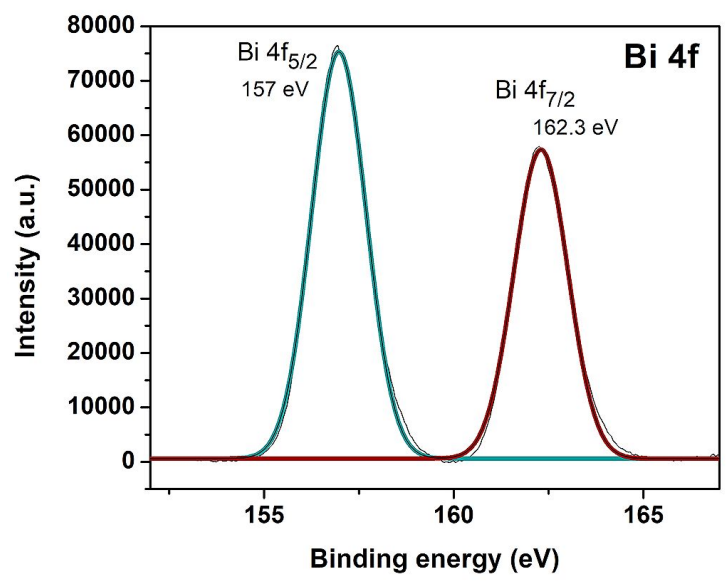

(a)

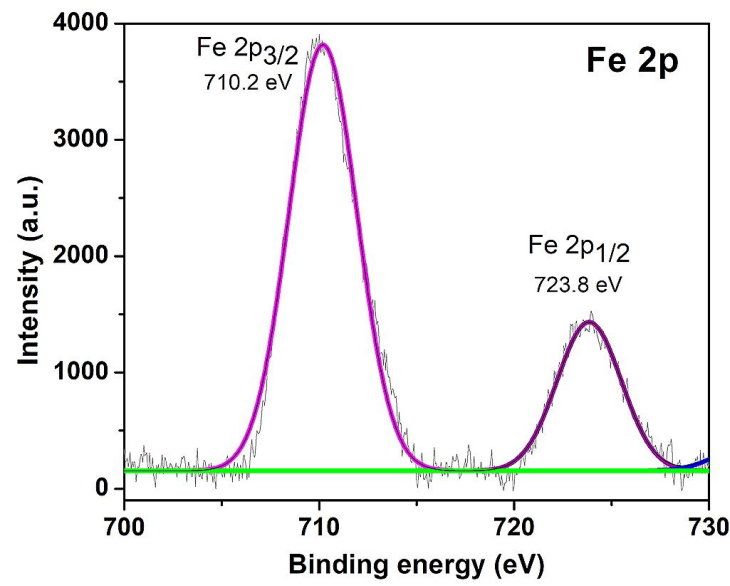

(c)

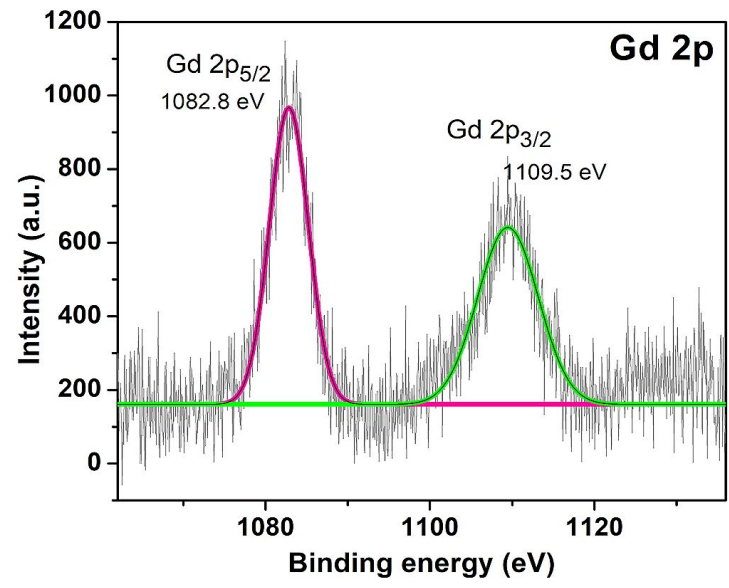

(b)

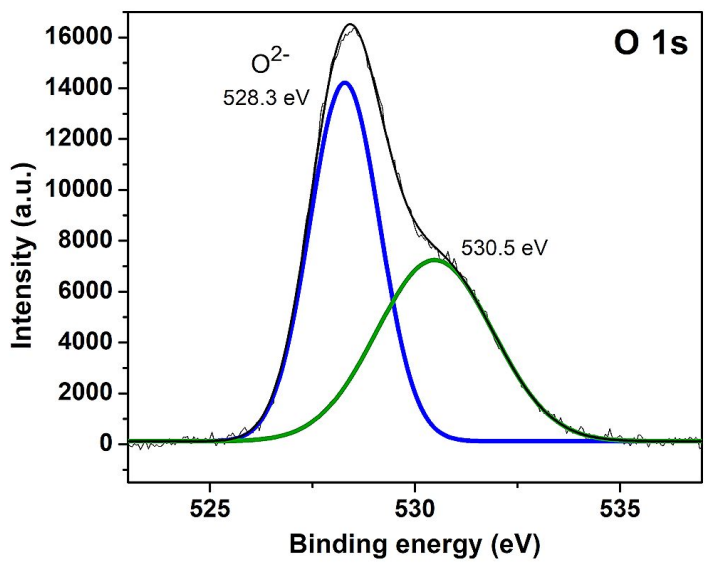

(d)

Fig. 5. Detailed XPS spectra for each component cation in $\mathrm{Bi}_{0.94} \mathrm{Gd}_{0.06} \mathrm{FeO}_{3}$ sample (a) $\mathrm{Bi} 4 \mathrm{f}$, (b) $\mathrm{Gd} 2 \mathrm{p}$, (c) $\mathrm{Fe}$ $2 \mathrm{p}$ and (d) O $1 \mathrm{~s}$.

indicating a ferromagnetic behavior. In addition, the substitution with $\mathrm{Gd}$ ions improves the magnetic properties of $\mathrm{Bi}_{0.94} \mathrm{Gd}_{0.06} \mathrm{FeO}_{3}$. The magnetization as a function of temperature in zero field (ZFC) and field cooled (FC) modes measured at $500 \mathrm{Oe}, 1000 \mathrm{Oe}$ and $5000 \mathrm{Oe}$, confirms the paramagnetic behavior of the compound. The magnetization curves have similar shapes for the applied fields of $500 \mathrm{Oe}$ and $1000 \mathrm{Oe}$, while at $5000 \mathrm{Oe}$, it is evident that there is a distinct difference in the ZFC and FC curves due to the high temperature difference between $50 \mathrm{~K}$ and $250 \mathrm{~K}$, as shown in Fig. 7. For all applied fields, a decrease in magnetization with the increase in temperature is observed, which shows a paramagnetic behavior in the ZFC curve, exhibiting the highest magnetization at the lowest temperature.

The superposition of the ZFC and FC magnetization curves, according to Basith et al. [29], is related with the dominant anti-ferromagnetic nature of solid, which presents the unmodified material, and the decrease in magnetization is due to the randomization of magnetic spins with the increase in temperature. According to the literature [21], it is known that $\mathrm{BiFeO}_{3}$ shows a G-type antiferromagnetic arrangement along (llll $\left.\begin{array}{lll}1 & 1 & 1\end{array}\right)$ or $\left(\begin{array}{lll}0 & 1 & 1\end{array}\right)$ facets, in 


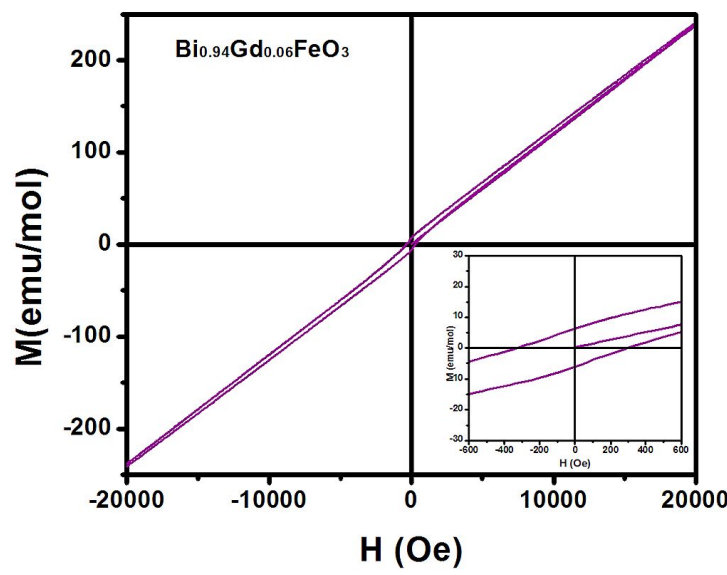

Fig. 6. Magnetization curves $\mathrm{M}-\mathrm{H}$ for $\mathrm{Bi}_{0.94} \mathrm{Gd}_{0.06} \mathrm{FeO}_{3}$ sample measured at $50 \mathrm{~K}$.

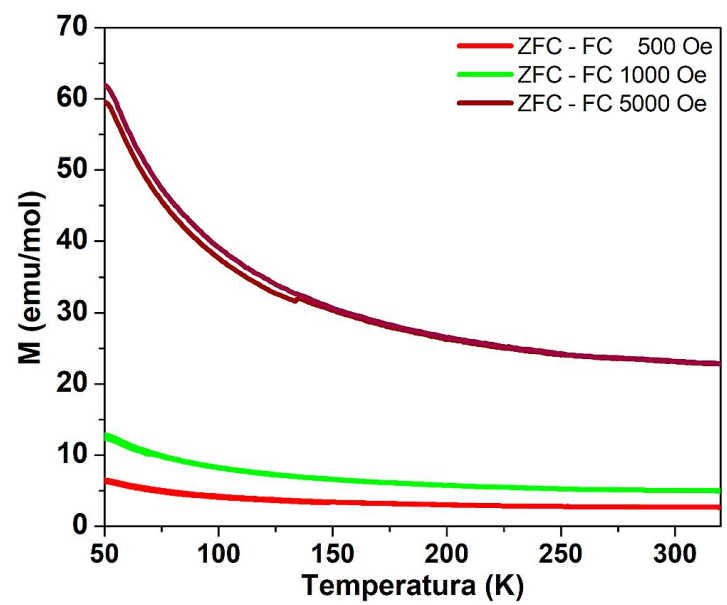

Fig. 7. ZFC and $\mathrm{FC}$ curves for $\mathrm{Bi}_{0.94} \mathrm{Gd}_{0.06} \mathrm{FeO}_{3}$ sample at $500 \mathrm{Oe}, 1000 \mathrm{Oe}$ and $5000 \mathrm{Oe}$.

its pseudocubic or rhombohedral structure. It may explain why the improvement in the magnetization can be attributed to the substitution with $\mathrm{Gd}$ ions at the bismuth site, which allows to obtain a magnetic moment that can be improved due to the low ionic radius of Gd. This effect induces distortion in the crystal structure and suppresses the spinspin configuration favoring a paramagnetic behavior $[14,30]$.

\section{Conclusion}

The solid-state reaction method was employed to obtain a sample of $\mathrm{Bi}_{0.94} \mathrm{Gd}_{0.06} \mathrm{FeO}_{3}$. The method was successful in comparison with the previous process in which the presence of a secondary phase in $\mathrm{Bi}_{0.94} \mathrm{Gd}_{0.06} \mathrm{FeO}_{3}$ sample was higher than in the current work. The results derived from XRD and Rietveld refinement confirm the distortion in the $\mathrm{BiFeO}_{3}$ structure, resulting from gadolinium modification that promotes stabilization of a $\mathrm{Fe}^{3+}$ valence state in bismuth ferrite and allows one to avoid phase segregation, which confirms the importance of the present investigation. The temperature dependent magnetization showed a significant increase in magnetization below $150 \mathrm{~K}$ at $5000 \mathrm{Oe}$, indicating a weak ferromagnetic behavior at low temperatures similar to a material with excellent properties. The analysis of X-ray photoelectron spectroscopy allowed us to establish that the obtained sample is composed mainly from $\mathrm{Fe}^{3+}$ cations, which contributes to stabilization of crystalline phase. The observed ferromagnetic character due to the distorted spin cycloid and ferromagnetic coupling between $\mathrm{Gd}^{3+}$ and $\mathrm{Fe}^{3+}$ ions is a relevant characteristic of the synthesized material.

\section{References}

[1] Wang D.H., Goh W.C., Ning M., Ong C.K., Appl. Phys. Lett., 88 (2006), 212907.

[2] Schiemer J., Withers R.L., Carpenter M.A., LiU Y., WANG. J.L., Norén L., Li Q., Hutchison W., J. Phys.-Condens. Mat., 24 (2012), 125901.

[3] Chaudhuri A., Mandal K., J. Magn. Magn. Mater., 353 (2014), 57.

[4] Rajput S.S., Katoch R., Sahoo K.K., Sharma G.N., Singh S.K., Gupta R., Garg A., J. Alloy. Compd., 621 (2015), 339.

[5] Tang P., Kuang D., Yang S., Zhang Y., J. Alloy. Compd., 656 (2016), 912.

[6] Gupta S., Tomar M., Gupta V., James A.R., Pal M., Guo R., Bhalla A., J. Appl. Phys., 115 (2014), 234105.

[7] Mohammadi S., Shokrollahi H., BaSiri M.H., J. Magn. Magn. Mater., 375 (2015), 38.

[8] Wang X., Zhang Y., Wu Z., Mater. Lett., 64 (2010), 486.

[9] Verma V., J. Alloy. Compd., 641 (2015), 205.

[10] Jeon N., Rout D., Won III K., Kang S.L., Appl. Phys. Lett., 98 (2011), 072901.

[11] DAI H.Y., Chen Z.P., LI T., LI Y.J., J. Rare Earth., 30 (2012), 1123. 
[12] Qian F.Z., Jiang J.S., GuO S.Z., Jiang D.M., Zhang W.G., J. Appl. Phys., 106 (2009), 084312.

[13] Guo R., FAng L., Dong W., Zheng F., Shen M., J. Phys. Chem. C, 114 (2010), 21390.

[14] Reddy V.R., Kothari D., Gupta A., Gupta S.M., Appl. Phys. Lett., 94 (2009), 082505.

[15] Lazenka V.V., Zhang G., Vanacken J., Makoed I.I., Ravinski A.F., Moshchalkov V.V., J. Phys. D Appl. Phys., 45 (2012) 125002.

[16] UniYal P., YADAV K.L., Mater. Lett., 62 (2008), 2858.

[17] Rao T.D., Karthik T., Asthana S., J. Rare Earth., 31 (2013), 370.

[18] Lin Y.H., JiAng Q., WANG Y., NAN C.W., Chen L., YU J., Appl. Phys. Lett., 90 (2007), 172507.

[19] Mejía J.A., Supelano G.I., Palacio C.A., Parra C.A., J. Phys. Conf. Ser., 614 (2015), 012003.

[20] Vijayasundaram S.V., Suresh G., Mondal R.A., KanaGAdurai R., J. Magn. Magn. Mater., 418 (2016), 30.

[21] Khomchenko V.A., ShVartsman V.V., Borisov P., Kleemann W., Kiselev D.A., Bdikin I.K., Vieira J.M., Kholkin A.L., Acta Mater., 57 (2009), 5137.

[22] Lotey G.S., Verma N.K., J. Nanopart. Res., 14 (2012), 742.
[23] Lotey G.S., Verma N.K., ?Chem. Phys. Lett., 574 (2013), 71.

[24] Hallam P.M., Mingot M.G., Kampouris D. K., BANKS C. E., RSC Adv., 2 (2012), 6672.

[25] Bellakki M.B., Manivannan V., J. Sol-Gel Sci. Techn., 53 (2010), 184.

[26] Kumar P., Kar M., Mat. Sci. Semicon. Proc., 31 (2015), 262.

[27] Xu X., Tan G., LiU W., Hao H., Ren H., J. Alloy. Compd., 622 (2015), 477.

[28] Suresh P., Babu P.D., SRinath S., Ceram. Int., 42 (2016), 4176.

[29] Basith M.A., Billah A., Jalil M.A., Yesmin N., Sakib M.A., AshiK E., Hoque S.M., Chowdhury S.S., Hossain M.S., Firoz S.H., Ahmmad B., J. Alloy. Compd., 694 (2016), 792.

[30] Pradhan S.K., Das J., Rout P.P., Das S.K., Mishra D.K., SAhU D.R., Pradhan A.K., SRINIVASU V.V., NAYAK B.B., VERMa S., ROUL B.K., ?J. Magn. Magn. Mater., 322 (2010), 3614. 